\title{
Mathematical Modelling of Thermal Degradation Kinetics of Ascorbic Acid in Brassica Carinata
}

\author{
Gebrehana Ashine $^{1 *}$ and Tadele Andargie ${ }^{2}$ \\ ${ }^{1}$ Bahir Dar University, Bahir Dar Institute of Technology, School of Chemical and Food Engineering, \\ P.O. Box 26, Bahir Dar, Ethiopia \\ ${ }^{2}$ Bahir Dar University, Bahir Dar Institute of Technology, School of Chemical and Food Engineering, \\ P.O. Box 26, Bahir Dar, Ethiopia
}

\begin{tabular}{|c|c|}
\hline \multirow{2}{*}{$\begin{array}{l}\text { Abstract } \\
\text { Ethiopian green collard (Brassica Carinata) locally named yeabesha gomen is one of the } \\
\text { important vegetable for ascorbic acid source in our society. However, adequate study has } \\
\text { not been conducted to exploit the potential of this indigenous vegetable. The kinetics of } \\
\text { ascorbic acid thermal degradation in yeabesha gomen as well as in pure ascorbic acid } \\
\text { solution over a temperature range of } 60-120^{\circ} \mathrm{C} \text { (isothermal temperature process) for up to } \\
60 \text { minutes has been studied. The thermal degradation of ascorbic acid in yeabesha gomen } \\
\text { fitted first-order reaction kinetic model where the rate constant increased from } 0.0146 \text { to } \\
0.051 \mathrm{~min}^{-1} \text { with an increase in the temperature from } 60 \text { to } 120^{\circ} \mathrm{C} \text { respectively. The } \\
\text { temperature dependence of degradation was adequately modeled by the Arrhenius } \\
\text { equation with } \mathrm{R}^{2}=0.977 \text { and RMSE }=0.0733 \text {. Activation energy for ascorbic degradation } \\
\text { kinetics of yeabesha gomen was found to be } 21.85 \mathrm{kJmol}{ }^{-1} \text {. This lower activation energy } \\
\text { value indicates that ascorbic acid in yeabesha gomen is quite susceptible to thermal } \\
\text { processes. The outputs this work would be helpful to design and control practical thermal } \\
\text { processing situations that minimize the loss of ascorbic acid in Ethiopian green collard as } \\
\text { well as other leafy green vegetables contained ascorbic acid compounds. }\end{array}$} & Article Information \\
\hline \multirow{10}{*}{$\begin{array}{l}\text { Ethiopian green collard (Brassica Carinata) locally named yeabesha gomen is one of the } \\
\text { important vegetable for ascorbic acid source in our society. However, adequate study has } \\
\text { not been conducted to exploit the potential of this indigenous vegetable. The kinetics of } \\
\text { ascorbic acid thermal degradation in yeabesha gomen as well as in pure ascorbic acid } \\
\text { solution over a temperature range of } 60-120^{\circ} \mathrm{C} \text { (isothermal temperature process) for up to } \\
60 \text { minutes has been studied. The thermal degradation of ascorbic acid in yeabesha gomen } \\
\text { fitted first-order reaction kinetic model where the rate constant increased from } 0.0146 \text { to } \\
0.051 \mathrm{~min}^{-1} \text { with an increase in the temperature from } 60 \text { to } 120^{\circ} \mathrm{C} \text { respectively. The } \\
\text { temperature dependence of degradation was adequately modeled by the Arrhenius } \\
\text { equation with } \mathrm{R}^{2}=0.977 \text { and RMSE }=0.0733 \text {. Activation energy for ascorbic degradation } \\
\text { kinetics of yeabesha gomen was found to be } 21.85 \mathrm{kmol} \mathrm{J}^{-1} \text {. This lower activation energy } \\
\text { value indicates that ascorbic acid in yeabesha gomen is quite susceptible to thermal } \\
\text { processes. The outputs this work would be helpful to design and control practical thermal } \\
\text { processing situations that minimize the loss of ascorbic acid in Ethiopian green collard as } \\
\text { well as other leafy green vegetables contained ascorbic acid compounds. }\end{array}$} & Article History: \\
\hline & Received : 06-01-2015 \\
\hline & : 23-03-2015 \\
\hline & Accepted : 25-03-2015 \\
\hline & Keywords: \\
\hline & scorbic acid \\
\hline & Yeabesha gomen \\
\hline & Activation energy \\
\hline & $\begin{array}{l}\text { Thermal degradation } \\
\text { Kinetics }\end{array}$ \\
\hline & \\
\hline & \\
\hline
\end{tabular}

\section{INTRODUCTION}

Fruits and vegetables undergo various handling, storage and processing steps before they are consumed (Nisha et al., 2005). Mathematical analysis of nutrient changes can give the basis for predicting the effects of varying process variables on end product quality, and therefore the basis for both process design and control. Vitamin $\mathrm{C}$, also known as ascorbic acid, is a water-soluble vitamin found in fruits and vegetables. It is a good indicator of the impact of thermal processing and storage on product quality since it is thermo-labile and sensitive to oxidation (Benzie, 1999; Davey et al., 2000).

Cooking leafy green vegetables at high temperature destroys ascorbic acid since it easily leaches into the cooking water being a water-soluble vitamin. The extent of the loss of ascorbic acid depends upon variations in cooking methods and periods (Khwairakpam B. and Balwinder S., 2014). Kinetic models of thermal destruction are often considered to be essential to design new processes to assure a safe food product and give maximum retention of quality (Avila and Silva, 1999). For the design of an optimized process that can lead to a maximized preservation of phytochemicals, kinetic modeling is necessary to derive basic kinetic information for a system in order to describe the reaction rate as a function of experimental variables and hence, to predict changes in a particular food during processing (Van Boekel, 2008; Yu et al., 2011).

In general, many scholars conducted researches on quality degradation reactions of foods and concluded as they are modeled by the conventional zero, first, or second order kinetics (Tauokis et al., 1997; Giannakorou and Tauokis, 2003; Rekha Nisha et al., 2004; Zanoni et al., 2005; Nisha et al., 2005; Rodrigo et al., 2007; Sothornvit and Kiatchanapaibul, 2009). However, published literatures were not found on the thermal degradation kinetics of ascorbic acid in Ethiopian green collard (yeabesha gomen). Thus, the goal of this research work was to mathematically model the thermal degradation kinetic of ascorbic acid in Ethiopian green collard over temperature range of $60-120^{\circ} \mathrm{C}$ helping for further cooking process design and control for maximum ascorbic acid retention.

\section{MATERIALS AND METHODS}

\section{Chemicals and Reagents}

Meta Phosphoric Acid (MPA), L-Ascorbic Acid, Glacial acetic acid, 2, 6-dichlorophenol-indophenol, Sodium acetate and Xylene, were purchased from Micron Plc, 
Gebrehana Ashine and Tadele Andargie

Addis Ababa, Ethiopia. All the chemicals used were of analytical reagent grade.

\section{Sample Collection and Transportation}

Well known and abundantly consumed green collard (Brassica Carinata) was collected from Bahir Dar city local market consulting Adet Agricultural research institute. All samples of raw material were packed in polyethylene bags, placed in Ice-box and transported to BDU, Institute of Technology, School of chemical and Food engineering Laboratories for experimental work.

\section{Heat treatments}

After proper cleaning of raw material through washing with cold water, experiment was conducted by $6 * 5 * 3$ Full Factorial Design at different temperature levels $(60,70$ $80,90,100$ and $120^{\circ} \mathrm{C}$ ) for $0-60$ minutes $(0,15,30,45$ and $60 \mathrm{~min}$ ) set according to Nisha et al (2005) with little modification. A water-bath was used as a heating device. (For $120^{\circ} \mathrm{C}$ an autoclave was used). The degradation kinetics of pure ascorbic acid solution was studied taking the same ascorbic acid concentration as that of the initial concentration of the model system (Ethiopian green collard).

Samples (about $10 \mathrm{~g}$ ) was transferred into a $100 \mathrm{ml}$ beaker containing $40 \mathrm{ml}$ of distilled water and pre-heated to the particular temperature at which the studies done. Samples, along with water, was withdrawn periodically and immediately analyzed for ascorbic acid.

\section{Determination of Ascorbic Acid}

Ascorbic acid was determined following the method stated by Nisha et al. (2005). Clearly, Standard indophenol's solution was prepared by dissolving $0.08 \mathrm{~g} 2$, 6 -dichlorophenol-indophenol in water and diluted to $100 \mathrm{ml}$ and filtered. The heat-treated Ethiopian green collard sample, along with the water, was ground to a paste with minimum amount of $3 \%$ metaphosphoric acid in a mortar and pestle. Then, it was transferred into a $100 \mathrm{ml}$ volumetric flask with the help of a funnel rinsing mortar and pestle several times with small amounts of $3 \%$ metaphosphoric acid and added back to the volumetric flask. The volume was made up to $100 \mathrm{ml}$ using $3 \%$ metaphosphoric acid, mixed thoroughly, and then filtered through filter paper. The filtrate $(2 \mathrm{ml})$ was placed in a $50 \mathrm{ml}$ stoppered conical flask followed by $2 \mathrm{ml}$ of acetate buffer $(\mathrm{pH} 4.0$, prepared by mixing 1 litre of $50 \%$ $\mathrm{CH}_{3} \mathrm{COONa} \cdot 3 \mathrm{H}_{2} \mathrm{O}$ with 1 litre of glacial acetic acid), $3 \mathrm{ml}$ of 2,6-dichlorophenol-indophenol solution and $15 \mathrm{ml}$ of xylene. It was shaken vigorously for 10 seconds and the solvent was allowed to separate. The lower water layer was pipetted out and the color of the xylene layer was measured at $520 \mathrm{~nm}$ using a spectrophotometer. All the experiments were done in triplicate.

\section{Determination of Kinetic Parameters for Ascorbic Acid Degradation}

The general reaction rate equation for ascorbic acid degradation kinetic is expressed by (Libuza and Riboh, 1982)

$$
\frac{-d[C]}{d t}=k_{T}[C]^{n}
$$

Where, $[\mathrm{C}]$ is ascorbic acid concentration (mgg-1), $\mathrm{k}_{\mathrm{T}}$ is the reaction rate constant $\left(\mathrm{min}^{-1}\right), \mathrm{n}$ is order of the reaction and $t$ is the time $(\mathrm{min})$.

The dependence of $k_{T}$ on temperature was described by the Arrhenius model:
Sci. Technol. Arts Res. J., Jan-March 2015, 4(1): 115-119

$$
k_{T}=k_{0} \exp \left(\frac{-E_{a}}{R T}\right)
$$

Where, $k_{0}$ is the frequency factor $\left(\mathrm{min}^{-1}\right), E_{a}$ is the activation energy $(\mathrm{kJ} / \mathrm{mol}), R$ is the ideal gas constant $(8.314 \mathrm{~J} / \mathrm{mol} . \mathrm{K}), \mathrm{T}$ is the actual temperature $(\mathrm{K})$, and $\mathrm{t}$ is the time $(\mathrm{min})$.

Kinetic parameters for ascorbic acid degradation were estimated by a common two-step linear regression method (Esteve et al. 1998, 1999). In the first regression, the logarithm of the values of ascorbic acid content was plotted against heat treatment time to obtain $\mathrm{k}_{\mathrm{T}}$ values at each temperature. In the second step, the natural logarithm of the reaction rate constant was regressed against $(1 / T)$. The slope of this curve, the Arrhenius plot, is equal to $R_{a}$ and allowed calculation of activation energy.

\section{Statistical Data Analysis}

All experiments were done in triplicate. Data were expressed as means \pm standard error (SE) of triplicate experiments. All the statistical analysis and data were fitted to models using JMPIN 5.0.1 statistical software Microsoft Office Excel 2007. The coefficient of determination $\left(R^{2}\right)$ and root mean square error (RMSE) were used as criteria for adequacy of model fit.

\section{RESULTS}

The initial concentration of ascorbic acid in yeabesha gomen was found to be $38.14 \pm 0.19 \mathrm{mg} / 100 \mathrm{~g}$. The results show the change of ascorbic acid concentration of yeabesha gomen and pure solution of ascorbic acid standard through the duration of $0-60$ minutes at different temperature values (Figure 1 to 6 ). It can be seen on the graph that the thermal degradation trend of yeabesha gomen is more or less similar to pure ascorbic acid solutions up to a temperature of $90^{\circ} \mathrm{C}$. Beyond $90^{\circ} \mathrm{C}$, ascorbic acid was more stable in yeabesha gomen, indicating the protective effect of other constituents of it. It is also clear from the data that the longer exposure to high temperatures highly destruct ascorbic acid in pure ascorbic acid solutions.

The rate constants were determined from the slopes of the regression lines $\ln \left(\mathrm{C} / \mathrm{C}_{0}\right)$ with treatment time are presented fitting to first -order equations. The rate constants for ascorbic acid degradation in yeabesha gomen were increased from $0.0146 \mathrm{~min}^{-1}$ at $60^{\circ} \mathrm{C}$ to $0.051 \mathrm{~min}^{-1}$ at $120^{\circ} \mathrm{C}$. A similar trend was observed for pure ascorbic acid solution (Table 1).

Activation energies $\left(E_{a}\right)$ values were calculated as a product of gas constant $(R)$ and the slope of the graph obtained by plotting Ink versus $1 / T$ after linearizing Arrhenius equation. The computed values of activation energy $\left(E_{a}\right)$ and frequency factor $\left(k_{o}\right)$ from non-isothermal data of yeabesha gomen and ascorbic acid standard are reported in Table 2 fitting to first and-order kinetics models.

In addition to $E_{a}$, decimal reduction time (D) and Halflife time $\left(t_{1 / 2}\right)$ values for ascorbic acid in yeabesha gomen and in pure ascorbic acid solution were presented in Table 3. Half-life time is the time required for ascorbic acid to degrade $50 \%$ of its original value, was calculated from the rate constant as $0.693 / \mathrm{k}$. Decimal reduction time; the time required to reduce the ascorbic acid concentration by $90 \%$ was also calculated from rate constant as $\mathrm{k} / 2.303$. 
Gebrehana Ashine and Tadele Andargie

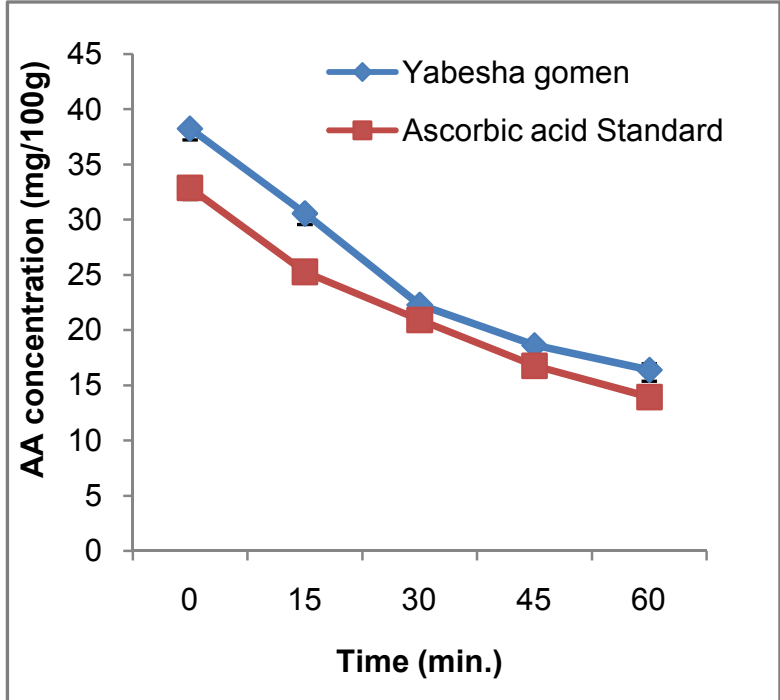

Figure 1: Degradation rate of ascorbic acid concentration at $60^{\circ} \mathrm{C}$

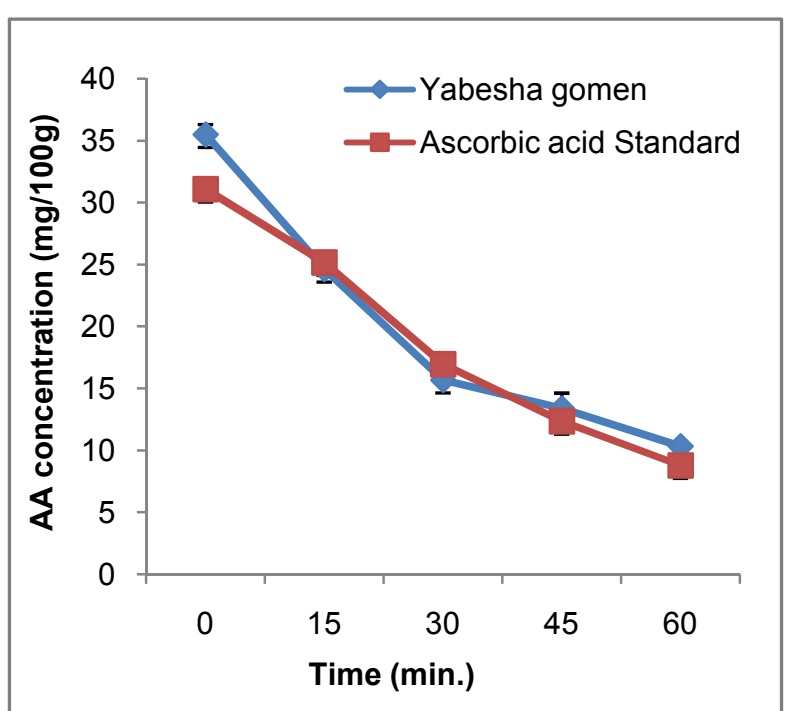

Figure 3: Degradation rate of ascorbic acid concentration at $80^{\circ} \mathrm{C}$

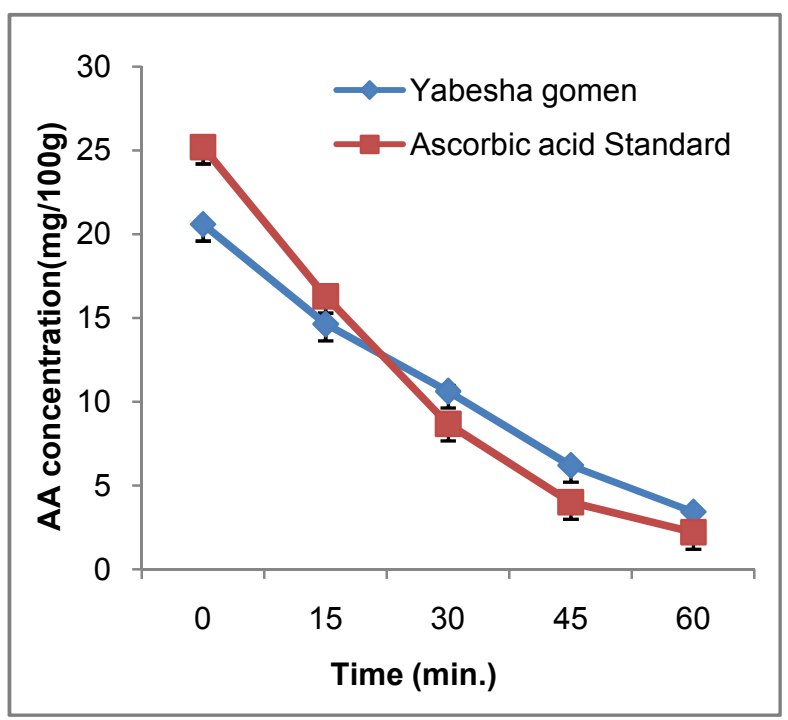

Figure 5: Degradation rate of ascorbic acid concentration at $100^{\circ} \mathrm{C}$
Sci. Technol. Arts Res. J., Jan-March 2015, 4(1): 115-119

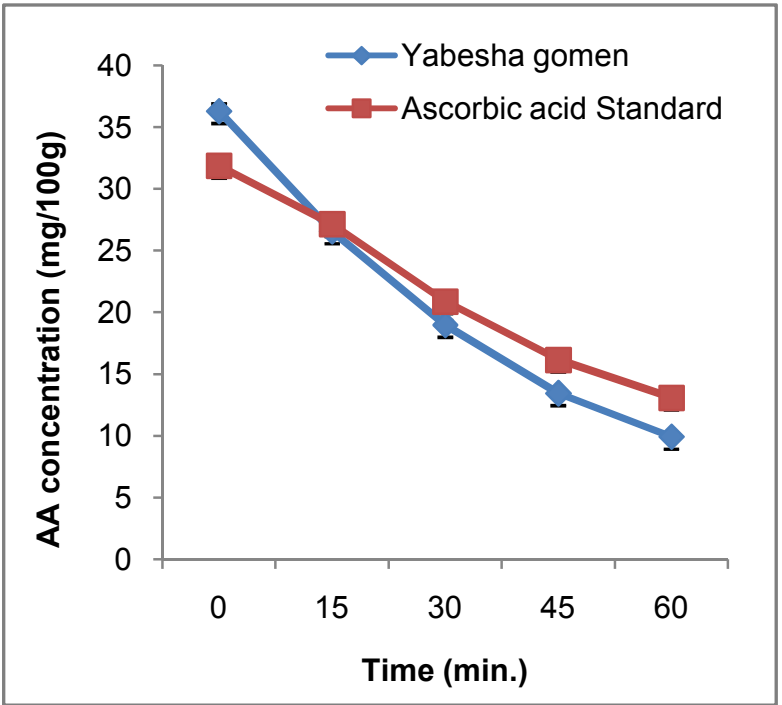

Figure 2: Degradation rate of ascorbic acid concentration at $70^{\circ} \mathrm{C}$

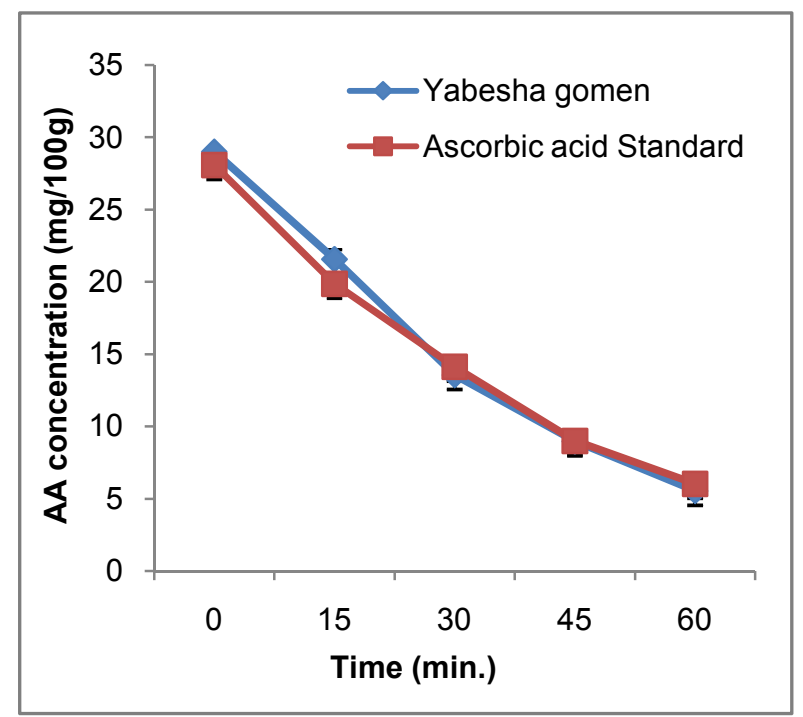

Figure 4: Degradation rate of ascorbic acid concentration at $90^{\circ} \mathrm{C}$

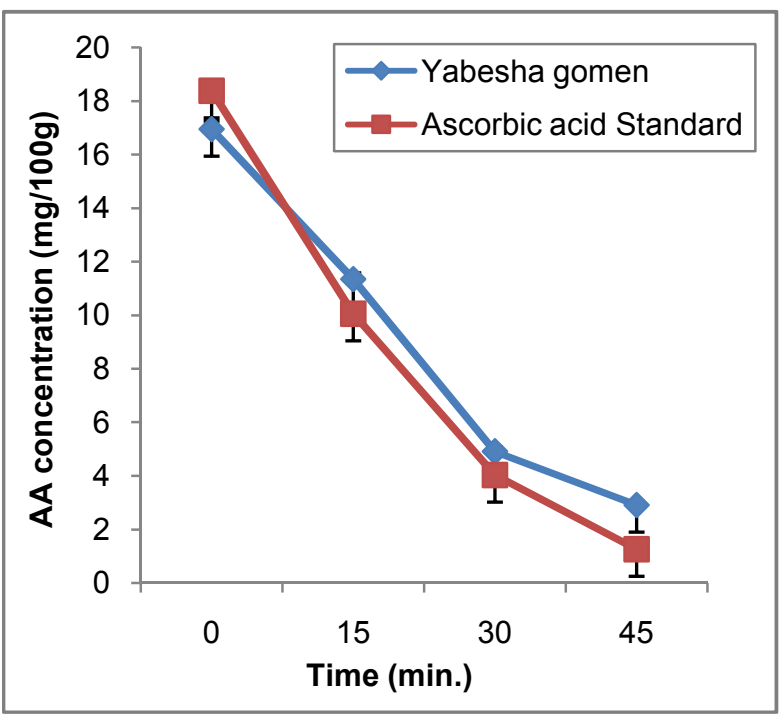

Figure 6: Degradation rate of ascorbic acid concentration at $120^{\circ} \mathrm{C}$ 
Table 1: Goodness of fitting first kinetics models to determine rate constants of ascorbic acid in yeabesha gomen

\begin{tabular}{cccccccc}
\hline \multirow{2}{*}{ Treated Sample } & & \multicolumn{7}{c}{ Temperature $\left({ }^{\circ} \mathbf{C}\right)$} \\
\cline { 3 - 8 } & & $\mathbf{6 0}$ & $\mathbf{7 0}$ & $\mathbf{8 0}$ & $\mathbf{9 0}$ & $\mathbf{1 0 0}$ & $\mathbf{1 2 0}$ \\
\hline \multirow{3}{*}{ Ethiopian green collard } & $\mathrm{k}$ & 0.0146 & 0.0181 & 0.0212 & 0.0287 & 0.0294 & 0.051 \\
& $\mathrm{R}^{2}$ & 0.993 & 0.996 & 0.973 & 0.995 & 0.991 & 0.997 \\
& $\mathrm{RMSE}$ & 0.0311 & 0.03 & 0.0814 & 0.0504 & 0.0725 & 0.0638 \\
\hline \multirow{3}{*}{ Pure ascorbic acid solution } & $\mathrm{k}$ & 0.0142 & 0.0167 & 0.0243 & 0.02585 & 0.03465 & 0.0673 \\
& $\mathrm{R}^{2}$ & 0.995 & 0.998 & 0.998 & 0.994 & 0.971 & 0.984 \\
& $\mathrm{RMSE}$ & 0.0258 & 0.0155 & 0.0263 & 0.0511 & 0.1918 & 0.2212 \\
\hline
\end{tabular}

RMSE- root mean square error, $\mathrm{R}^{2}$ - correlation coefficient, k-rate constant

Table 2: Fitting Arrhenius equation to first kinetics models of ascorbic acid degradation in yeabesha gomen and pure ascorbic acid solution

\begin{tabular}{|c|c|c|c|c|}
\hline Sample and pure Ascorbic Acid solution & $k_{o}\left(\min ^{-1}\right)$ & $\mathrm{E}_{\mathrm{a}}\left(\mathrm{kJ} \mathrm{mol}^{-1}\right)$ & $\mathbf{R}^{2}$ & RMSE \\
\hline Yeabesha gomen & 37.75 & 21.85 & 0.977 & 0.0733 \\
\hline Ascorbic acid standard & 533.4 & 29.54 & 0.990 & 0.0805 \\
\hline
\end{tabular}

Table 3: Half-life $\left(t_{1 / 2}\right)$ and decimal reduction (D) values of ascorbic acid in yeabesha gomen and in pure ascorbic acid solution at different temperature values

\begin{tabular}{ccccc}
\hline Temp. & \multicolumn{2}{c}{ Yeabesha gomen } & \multicolumn{2}{c}{ Ascorbic acid standard } \\
\cline { 2 - 5 }$\left(\mathbf{~}^{\circ} \mathbf{C}\right.$, $(\mathbf{m i n})$ & $\mathbf{D}(\mathbf{m i n})$ & $\mathbf{t}_{1 / 2}(\mathbf{m i n})$ & $\mathbf{D}(\mathbf{m i n})$ \\
\hline 60 & 47.5 & 157.7 & 48.8 & 162.2 \\
70 & 38.3 & 127.2 & 41.5 & 137.9 \\
80 & 32.7 & 108.6 & 28.5 & 94.8 \\
90 & 31.1 & 80.2 & 26.8 & 89.1 \\
100 & 27.5 & 78.3 & 20.0 & 66.5 \\
120 & 13.6 & 45.2 & 10.3 & 34.2 \\
\hline
\end{tabular}

\section{DISCUSSION}

\section{Thermal Degradation Kinetic of Ascorbic Acid of Ethiopian Green Collard}

The ascorbic acid content decreased significantly $(p \leq 0.05)$ on heating at different treatment times. However, heating at $120^{\circ} \mathrm{C}$ for $60 \mathrm{~min}$ had the most deleterious effect on the AA content of both yeabesha gomen and Ascorbic acid standard with complete destruction. The loss observed when Ethiopian green collard (yeabesha gomen) was subjected to heat is in agreement with the work of Babalola et al (2010) who confirmed that ascorbic acid levels in green leafy vegetables are temperature dependent. Lee and Kader (2000) stated that ascorbic acid is easily oxidized, especially in aqueous solutions and losses are enhances by higher temperatures. Furthermore, Burg and Fraile (1995) showed that the loss of vitamin $C$ at the cooking time was mainly due to the enzymatic destruction. Nicoleta and co-workers (2009) also reported that the rate of degradation of vitamin $\mathrm{C}$ depends on the temperature which is a critical factor involved in its destruction and prolonging of the heating time resulted in additional losses by thermal destruction.

\section{Kinetics Analysis and Mathematical Modeling}

The degradation kinetics of most food nutrients are described by fitting zero or first-order kinetic model to the experimental data (Martins et al., 2000; Gonçalves et al., 2010). Regression analysis was applied to calculate the reaction rate constant for each experimental data (isothermal) of both yeabesha gomen and ascorbic acid standard. Root mean square error (RMSE) and Correlation coefficient $\left(R^{2}\right)$ were used as statistical measures for comparison of the experimental and model simulated values.

In this research work, first-order kinetic model was fitted the experimental data with higher $\mathrm{R}^{2}$ value, ranging from 0.971-0.998 with lower RMSE (Table 1) in confirmation of those previously reported (Johnson et al.
1995; Esteve et al., 1999; Lee and Chen 1998). Kabasakalis and co-workers (2000) study also indicated that ascorbic acid degradation follows first-order kinetics in aqueous solutions over a pH range 3.52-7.22.

At specific time and temperature the concentration of ascorbic acid exists in Ethiopian green collard can be determined using the equation:

$$
C_{A}=C_{A 0} \exp \left(-k_{T} t\right)
$$

Where, $\mathrm{C}_{\mathrm{A}}$ is ascorbic acid concentration at treatment $\mathrm{t}$ and $\mathrm{C}_{\mathrm{AO}}$ is the initial ascorbic acid concentration at time $\mathrm{t}$ zero.

Dependence of the rate constant on temperature obeyed the Arrhenius relationship $\left(R^{2} \geq 0.977\right.$, RMSE $\leq$ $0.0805)$ as fitted to first-order kinetic model. The $E_{a}$ value of $21.85 \mathrm{~kJ} \mathrm{~mol}^{-1}$ obtained in the present study is lower than the values of $81.67 \mathrm{kJmol}^{-1}$ for pomegranate juice (Ranu Paul and Uma Ghosh, 2012), $47.5 \mathrm{kJmol}^{-1}$ for rose hip pulp (Mustafa et al, 2003), $75 \mathrm{kJmol}^{-1}$ for cupuacu (Vieira et al. 2000) and $115.5 \mathrm{kJmol}^{-1}$ for orange juice (Johnson et al. 1995) but in good agreement with the values of $14.4-47.4 \mathrm{kJmol}^{-1}$ for guava fruits stored at 30 and $50^{\circ} \mathrm{C}$ (Uddin et al. 2002)

This lower activation energy indicates that ascorbic acid in yeabesha gomen is quite susceptible to thermal processes. The result is in accordance with Nisha and coworkers (2005) finding of $18.37 \mathrm{kJmol}^{-1}$ as activation energy of ascorbic acid in drumstick leaves.

Both half-life and $D$ values are lower than those previously reported for rose hip pulp (Mustafa et al., 2003) through temperature ranged from 70 to $95^{\circ} \mathrm{C}$ and drumstick leaves from $50-120^{\circ} \mathrm{C}$ (Nish et al., 2005). Based on the information of half-life time and $D$ values, cooker can predict the retention and loss of ascorbic acid at specific treatment temperature compromising the well cooked and edibility of the green collard. 
Gebrehana Ashine and Tadele Andargie

\section{CONCLUSION}

The study showed that the thermal degradation of ascorbic acid content increases with time and temperature of processing. The degradation of ascorbic acid in cabbage and yeabesha gomen can be well described by an overall first order reaction and the temperature dependency of rate constant was adequately fitted Arrhenius equation with correlation coefficient $\left(R^{2}=0.977\right)$ and RMSE $=0.0733$ for yeabesha gomen and $R^{2}=0.99$, RMSE $=0.0805$ for pure ascorbic acid solution. Activation energy for ascorbic degradation kinetics of yeabesha gomen was $21.85 \mathrm{kJmol}^{-1}$. Ascorbic acid content of yeabesha gomen was decreased under all treatment times of the two cooking methods employed for this study, with greater losses occurring in pressure cooking method. Since cooking of yeabesha gomen is inevitable, it is advisable to add other fruits and vegetables to our daily meal with yeabesha gomen to ensure regular and adequate intake of vitamin $C$ to meet up the US daily reference intake of 75 and $90 \mathrm{mg} /$ day for women and men respectively (Szeto et al., 2002). This research outputs would be helpful to design and control practical thermal food processing situations enable to minimize the degradation of ascorbic acid in yeabesha gomen as well as other leafy green vegetables contained ascorbic acid compounds.

\section{Acknowledgements}

The funding and laboratory facility provided by Bahir Dar Institute of Technology are admiringly acknowledged. The authors would like to express heartfelt gratitude to Adet Agriculture Research Institute for knowing the abundant yeabesha gomen consumed by our society.

\section{Conflict of Interest}

Conflict of interest none declared.

\section{REFERENCES}

Babalola OO,Tugbobo OS, Daramola AS (2010). Effect of processing on the vitamin $\mathrm{C}$ content of seven Nigerian green leafy vegetables. Advanced Journal of Food Science and Technology 2(6):303-305.

Benzie I.F F (1999). Prospective Functional Markers for Defining Optimal Nutritional Status: Vitamin C. Proc. Nutr. Soc. 58: 1-8.

Burg $P$ and Fraile $P$ (1995). Vitamin $C$ destruction during the cooking of a potato dish. Food Science and Technology 28: 506- 514.

Esteve MJ, Frigola A, Martorell L, Rodrigo C (1999). Kinetics of green asparagus ascorbic acid heated in a hightemperature thermoresistometer. Z LebensmittUntersuchForsch A/Food Res Technol 208:144-147.

Giannakorou M C Taoukis P S (2003). Kinetics modeling of vitamin $C$ loss in frozen leafy vegetables under storage conditions. Food chemistry 83:33-41.

Gonçalves, E. M., Pinheiro, J., Abreu, M., Brandão, T. R. S., \& Silva, C. L. M (2010). Carrot (Daucus carota L.) peroxidase inactivation, phenolic content and physical changes kinetics due to blanching. Journal of Food Engineering 97: 574-581.

Johnson JR, Braddock RJ, Chen CS (1995). Kinetics of ascorbic acid loss and non-enzymatic browning in orange juice serum: experimental rate constants. Journal Food Science 60: 502-504.
Sci. Technol. Arts Res. J., Jan-March 2015, 4(1): 115-119

Kabasakalis V, Siopidou D, Moshatou E (2000). Ascorbic acid content of commercial fruit juices and its rate of loss upon storage. Food Chemistry 70: 325-328.

Khwairakpam Bembem and Balwinder Sadana (2014). Effect of cooking methods on the nutritional composition and antioxidant activity of potato tubers. International Journal of Food and Nutritional Sciences 2: 26-30.

Lee S K \& Kader A A (2000). Preharvest and postharvest factors influencing vitamin $\mathrm{C}$ content of horticultural crops. Postharvest Biology and Technology 20: 207-220.

Libuza TP and Riboh D (1982). Theory and application of Arrhenius kinetics to the prediction of nutrient losses in foods. Journal Food Science 47: 66-74.

M.W. Davey, M.V . Montagu, D. Inze, M. Sanmartin, A. Kanellis, N. Smirnoff, I.F.F. Benzie, J. J. Strain, D. Favell and J. Fletcher (2000). Plant L-Ascorbic Acid: Chemistry, Function, Metabolism, Bioavailability and Effects of Processing. Journal of Science of Food \& Agriculture 80: 825-860.

Martins, S. I. F. S., Jongen, W. M. F., \& van Boekel, M. A. J. $S$ (2000). A review of Maillard reaction in food and implications to kinetic modelling. Trends in Food Science \& Technology 11: 364-373.

Mustafa K, Mehmet A, Nedim T, Irfan T (2004). Kinetic modeling of anaerobic thermal degradation of ascorbic acid in rose hip (Rosa Canina L) pulp. Journal of Food Quality 27: $311-319$.

Nicoleta Matei, Alina Soceanu, Simona Dobrinas, and Vasile Magearu (2009). Kinetic study of ascorbic acid degradation from grapes. Ovidius University Press 20(1):132-136.

Nisha PB, Rekha S, Aniruddha B (2005). A study on degradation kinetics of ascorbic acid in drumstick (Moringa Olifera) leaves during cooking. Journal of the Science of Food and Agriculture 85: 1953-1958.

Ranu Paul and Uma Ghosh (2012). Effect of thermal treatment on ascorbic acid content of pomegranate juice. Indian Journal of Biotechnology 11:309-313.

Sothornvit R., Kiatchanapaibul P. (2009). Quality and shelf life of washed fresh-cut asparagus in modified atmosphere packaging. Food Science and Technology 42:1484-90.

Szeto, Y.T., B. Tomlinson and I.F.F. Benzie (2002). Total antioxidant and ascorbic acid content of fresh fruits and vegetables: implications for dietary planning and food preservation. British Journal of Nutrition 87: 55-59.

Tauokis P., Labuza T.P., Saguy I.S. (1997). Kinetics of food deterioration and shelf life prediction. In: K.J. Valentas, E. Rostein, R.P. Singh (eds.), Handbook of food engineering practice. CRC Press, Boca Raton, USA.

Uddin MS, Hawlader MNA, Luo Ding, Mujumdar AS (2002). Degradation of ascorbic acid in dried guava during storage. Journal of Food Engineering 51: 21-26.

Van Boekel, M. A. J. S. (2008). Kinetic modeling of food quality: A Critical Review. Comprehensive Reviews in Food Science and Food Safety 7:144-158.

Vieira M.C., Teixeira A.A. and Silva C.L.M (2000). Mathematical modelling of the thermal degradation kinetics of vitamin $\mathrm{C}$ in cupuacu (Theobroma grandifolum). Nectar. Journal Food Engineering 43: 1-7.

Yu, K., Wu, Y., Hu, Z., Cui, S., \& Yu, X. (2011). Modeling thermal degradation of litchi texture: Comparison of WeLL model and conventional methods. Food Research International 44(7):1970-1976.

Zanoni B., Pagliarini E., Galli A., Laureati M. (2005). Shelf-life prediction of fresh blood orange juice. Journal of Food Engineering 70:512-517. 